\title{
Growth and condition indices in juvenile sole Solea solea measured to assess the quality of essential fish habitat
}

\author{
R. Amara ${ }^{1, *}$, T. Meziane ${ }^{2}$, C. Gilliers ${ }^{1}$, G. Hermel $^{1}$, P. Laffargue $^{1}$ \\ ${ }^{1}$ Université du Littoral Côte d'Opale, FRE ELICO 2816 CNRS, avenue Foch, 62930 Wimereux, France \\ ${ }^{2}$ UMR 5178, Biologie des Organismes Marins et Ecosystèmes, Département Milieux et Peuplements Aquatiques, MNHN, \\ CP 53, 61 rue Buffon, 75231 Paris CEDEX 05, France
}

\begin{abstract}
We used growth rates (estimated from otolith microstructure), morphometric (Fulton's K condition index) and lipid (triacylglycerols:sterols ratio, TAG:ST) condition indices measured on 0 -group juveniles of common sole, to compare the habitat quality of 7 nursery grounds with differing levels of anthropogenic pressure. Along the French coast of the Southern Bight of the North Sea and the Eastern English Channel, we compared 2 sites located in intensively developed and industrialised harbour areas (Dunkerque and Calais), 1 site in a medium and less industrialised harbour (Boulogne), 1 site near a large and polluted estuary (Seine) and 3 other sites located near small estuaries less subject to human pressure (Canche, Authie and Somme). Indicators of human disturbance as well as hydrological and biotic data were used to establish between-site differences in environmental quality. Our results indicate consistent differences in the growth and condition indices of 0 group sole among the 7 sites. Sole had the slowest growth (mean $\mathrm{G}=0.54 \mathrm{~mm} \mathrm{~d}^{-1}$ ) and lowest condition indices (mean $\mathrm{K}=1.07$; TAG:ST $=0.32$ ) at Dunkerque and Calais and the fastest growth (mean $\mathrm{G}=0.70 \mathrm{~mm} \mathrm{~d}^{-1}$ ) and highest condition indices (mean $\mathrm{K}=1.19$; TAG:ST $=2.18$ ) at the Authie, Canche and Somme estuaries. The indices measured in this study correlated well with anthropogenic disturbance and may provide a useful tool to assess habitat quality. Sites with highest sediment chemical contaminants had the lowest habitat quality and, through growth and lipid-storage limitation, could dramatically lower over-winter survival of the juveniles living in these nursery grounds.
\end{abstract}

KEY WORDS: Habitat quality $\cdot$ Nursery grounds $\cdot$ Growth $\cdot$ Condition $\cdot$ Juvenile flatfish

\section{INTRODUCTION}

The function of shallow coastal habitats as important nursery grounds for marine fishes has become an accepted ecological concept. However, all coastal areas are not equally important as nursery grounds (Pihl et al. 2005). Indeed, these areas are typically subjected to a variety of stressors, both natural and anthropogenic, which may impact and induce variability in juvenile fish growth, survival and thus subpopulation production and recruitment (Meng et al. 2001, Pihl et al. 2005). Many studies have shown that fish that grow faster or have higher levels of energy reserves are less vulnerable to predation than those in poor condition and are also more able to survive the over-winter period (Biro et al. 2004). Due to the importance of these habitats for recruitment and survival of juvenile fish, finding a way to assess the quality of these nursery habitats may help prevent loss of recruits in areas essential to sustain fish populations.

Since fish presumably grow more quickly in highquality habitats that are rich in food and provide 
the right set of environmental variables to promote growth, many studies have suggested that measuring fish growth may be a good way to assess habitat quality. Differences in fish growth rates have been observed along an anthropogenic gradient (Burke et al. 1993, Meng et al. 2001) and between coastal areas with differing levels of nutrients and human development (Able et al. 1999, Meng et al. 2000). At present, few studies have attempted to compare fish habitat quality with different biological indices related to indices of environmental quality.

The shallow marine coastal zones of the Southern Bight of the North Sea (SBNS) and the Eastern English Channel (EEC) provide nursery areas, identified as essential fish habitat, for a wide variety of commercial fish species, particularly flatfish (Amara 2003, Eastwood et al. 2003). However, this coastline is also characterised by substantial urban and industrial development, resulting in heavy inputs of chemical contaminants, as well as significant loss or alteration of marine habitat at some locations. Three important harbours are located along this coastline (Dunkerque, Calais and Boulogne). In addition to the considerable urban pressures, various industries (metallurgical and chemical industries and petroleum refineries) are responsible for a large variety of inputs of industrial effluents to the coastal waters. The main estuary of this region, the Seine estuary, is one of the most polluted in northeast Europe. In these heavily impacted areas, Henry et al. (2004) showed that individuals of several flatfish species displayed higher metal concentrations

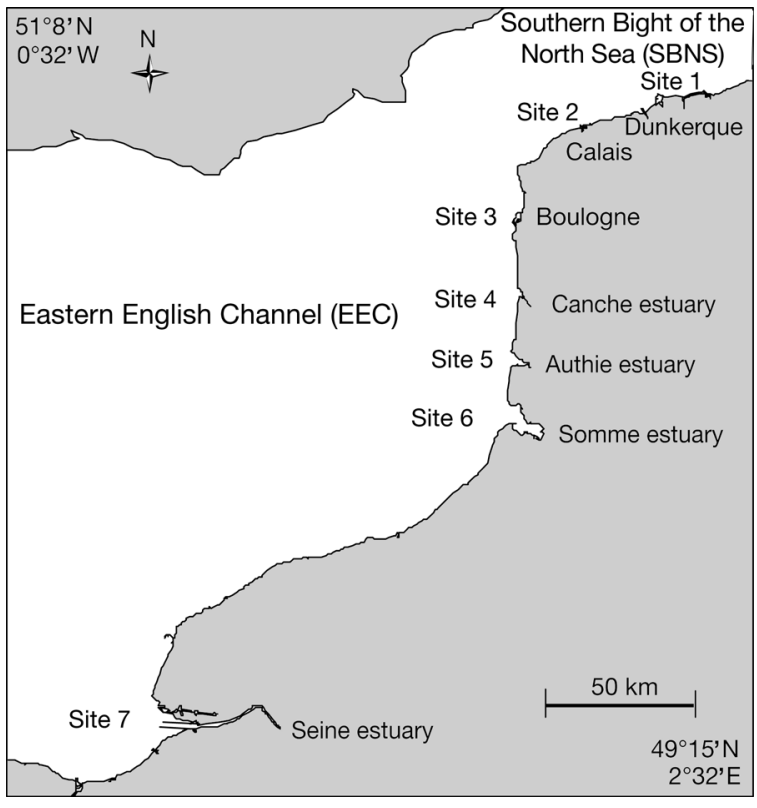

Fig. 1. Locations of the 7 nursery sites sampled in the Southern Bight of the North Sea (SBNS) and Eastern English Channel (EEC) than individuals from other estuarine sites along the coastline, such as the estuaries of Canche, Authie and Somme, which are less subject to human pressure.

Here we assessed whether marked differences in anthropogenic disturbance decreased the habitat quality of coastal nursery areas for common sole Solea solea L. We used 3 different indices (growth rates, morphometric and lipid condition indices) measured on young-of-the-year (YOY) juveniles to test for differences among 7 habitats in the SBNS and the EEC. Indices of environmental quality were used as indicators of human disturbance. The common sole was selected for the study because of its widespread distribution and commercial importance in the SBNS and the EEC. Juveniles of this species are restricted to very shallow coastal waters $(<20 \mathrm{~m}$ depth) during their first years of life (Amara 2003, Eastwood et al. 2003). Juvenile flatfishes that use nearshore habitats as nursery grounds may be especially sensitive to the effects of pollution and other types of habitat degradation, since they feed on benthic organisms and live in close association with the bottom sediments, where many contaminants accumulate (Adams 2002).

\section{MATERIALS AND METHODS}

Study area and sampling. The study area was located along the French coasts of the SBNS and the EEC (Fig. 1). Seven sites that were identified as important flatfish nursery grounds and that differed in terms of human activities were sampled. Sites 1 and 2 (Dunkerque and Calais) were located in intensively developed and industrialised harbour areas, site 3 in a medium and less industrialised harbour (Boulogne) and Site 7 (Seine) near a large and polluted estuary. Sites 4, 5 and 6 (Canche, Authie and Somme) are small estuaries characterised by little urban development and no industrialisation. The sampling surveys were carried out in September 2002. Autumn was chosen because it corresponds to the end of the growing season of YOY sole on nursery grounds before the over-winter period (Amara 2003). Fish were sampled with a $3 \mathrm{~m}$ beam trawl $(10 \times 10 \mathrm{~mm}$ mesh codend) equipped with 1 tickler chain. The trawl was towed from a small ship, the RV 'Sepia II' (12.5 $\mathrm{m}$ in length), and 3 or 4 hauls were made at each site. The trawling locations chosen were those parts of the nursery grounds that were likely to be exposed to anthropogenic disturbances. Juveniles were caught just outside the harbours of Dunkerque, Calais and Boulogne, and in the downstream portions of the rivers for the 4 estuarine sites of Canche, Authie, Somme and Seine. For each site, sub-samples of randomly selected 0-group sole juveniles were immediately individually frozen $\left(-20^{\circ} \mathrm{C}\right)$ for later analyses. The 
identification of the 0-group was done by analysing length-frequency distributions and then later confirmed by the absence of an annual ring on the sagittal otoliths. 0-group sole were measured for standard length to the nearest $\mathrm{mm}$ and weighed (wet weight and eviscerated weight) to the nearest $\mathrm{mg}$.

Environmental variables and chemical contamination data. Temperature and salinity data were recorded at each site with a CTD probe. Additional monthly temperature and salinity data were obtained from the RNO network 'Réseau National d'Observation de la qualité du milieu marin' ( ${ }^{\circ}$ RNO-MEDD/ IFREMER, Quadrige data bank). As a trophic indicator of the environment, we used mean benthic invertebrate biomass determined as ash-free dry weight (AFDW) $\mathrm{g} \mathrm{m}^{-2}$ (loss of weight of dry organisms after $6 \mathrm{~h}$ at $250^{\circ} \mathrm{C}$ ) for each site studied (data for the 3 harbours were obtained from J. M. Dewarumez pers. comm.; for the estuaries of Canche, Authie and Somme from Desroy et al. 2003; and for the Seine estuary from J. C. Dauvin pers. comm.). We calculated a mean benthic biomass from stations ( 3 to 5 ) selected to be representative of the surrounding fish sampling stations. At each station, 2 sediment samples for macrobenthos analysis were collected using a $0.25 \mathrm{~m}^{2}$ Hamon grab. The sampling method and data analyses were described by Desroy et al. (2003).

Data on sediment chemical contaminants (polycyclic aromatic hydrocarbons: PAHs; and heavy metals: Cd, $\mathrm{Cu}, \mathrm{Zn}, \mathrm{Hg}$ and $\mathrm{Pb}$ ) were obtained from 2 French national networks for the observation of the quality of the marine environment: the RNO and the REseau national de surveillance de la qualité de l'eau et des sédiments des POrts Maritimes (REPOM). The REPOM network is responsible for the analysis of environmental factors inside harbours. Data obtained from this network were those recorded at the mouth of these harbours. Because the estuaries of the Canche, the Authie, the Somme and the Seine are not covered by the REPOM network, we used data from the RNO collected at the mouths of these estuaries. In these 2 monitoring networks, we used the mean value calculated from 2 or 3 stations selected to be representative of their surroundings, and point sources of chemical contamination were deliberately avoided. Hence, the values used are taken as representative of the chemical contamination of the particular nursery ground.

Biological indicators. Growth rate index: Otolith (lapillus) microstructure analysis was used to estimate the age and the growth of 0 -group sole. The procedures used in otolith preparation were described by Amara et al. (1994). Age was estimated from the first well-defined increment of the lapillus, which corresponds to the mouth-opening 'check' and is located about $14 \pm 0.19 \mu \mathrm{m}$ from the nucleus. The average growth rate, $\mathrm{G}\left(\mathrm{mm} \mathrm{d}^{-1}\right)$, was computed for each 0-group sole using the following formula:

$$
\mathrm{G}=\left(\mathrm{SL}_{2}-\mathrm{SL}_{1}\right) / \text { age }
$$

where $\mathrm{SL}_{2}$ is the standard length (SL, mm) of the juvenile when caught and $\mathrm{SL}_{1}$ is the average $\mathrm{SL}(\mathrm{mm})$ at the mouth-opening stage for alcohol-preserved larvae. $\mathrm{SL}_{1}$ was considered to be a constant equal to $4 \mathrm{~mm}$ (Amara et al. 1994). The age is the time in days (d) after reaching the mouth-opening stage. Eleven otoliths $(8 \%$ of the total) had to be discarded because they could not be read unambiguously.

Condition indices: Two condition indices were estimated for each individual: a morphometric index and a lipid storage index related to the nutritional state of each fish. Fulton's K condition index assumes that heavier fish for a given length are in better condition and was calculated with the following formula:

$$
\mathrm{K}=100\left(\mathrm{~W} \mathrm{SL}^{-3}\right)
$$

where $\mathrm{W}$ is the fresh eviscerated body weight (mg) and $\mathrm{SL}$ is measured in mm. Fulton's K was also calculated with the fresh total body weight (mg) in order to compare it to literature data.

The second condition index was a lipid storage index based on the ratio of the quantity of triacylglycerols (TAG; reserve lipids) to the quantity of sterols (ST; structural lipids) in the fish. This ratio (TAG:ST) was selected as an index of nutritional status. The TAG content is dependent on the nutritional state of the fish as TAGs are a principal reserve of energy in teleosts and the first components to be mobilised during periods of stress, while sterol contents remain essentially unchanged during starvation (Galois et al. 1990). The amount of total lipids in each individual was measured on a sample of white muscle $(0.5 \mathrm{mg})$. Lipid extraction was conducted using the method of Bligh \& Dyer (1959) slightly modified as described by Meziane \& Tsuchiya (2000).

Statistics were performed with Xlstat 2007 and R software. Relationships between fish size (SL) and the 3 indices were first tested using Pearson correlations. To evaluate the link between fish variables (growth and condition indices), correlation coefficients were calculated. Differences in fish growth and condition among sites were analysed using the non-parametric Kruskal-Wallis test and the Dunn test (joint ranking test) for post hoc pairwise comparisons. Hierarchical clustering was used to regroup sites as a function of their similarity using a similarity matrix based on Euclidian distances and the method of Ward (Gordon 1999) for clustering purposes. To identify the role of environmental and chemical contamination variables in site differentiation, we performed principal component analysis (PCA) on logarithmically transformed data. 

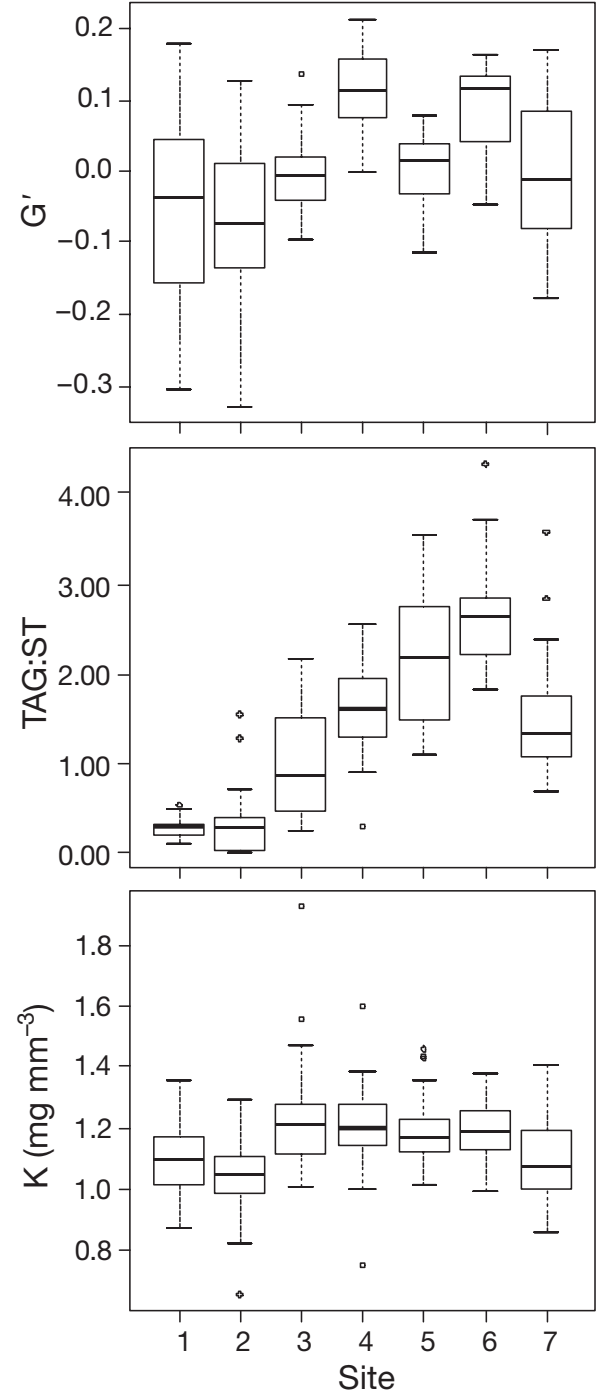

Fig. 2. Solea solea. Mean growth index $\left(\mathrm{G}^{\prime}\right)$, triacylglycerols: sterols ratio (TAG:ST) and Fulton's condition index (K) for 0group sole caught in 7 nursery grounds. The boxes represent the interquartile range containing $50 \%$ of the values. The whiskers extend to the highest and lowest values, excluding outliers. The line across the box indicates the median. For site names see Table 1

\section{RESULTS}

Temperature and salinity were not greatly different between the nursery sites (Table 1). Temperature varied from 17.69 to $18.62^{\circ} \mathrm{C}$ and salinity from 30.26 to $34.22 \mathrm{psu}$. Mean benthic invertebrate biomass ranged from 48.7 to $0.51 \mathrm{AFDW} \mathrm{g} \mathrm{m}^{-2}$, with the highest values recorded at Calais and the Seine estuary and the lowest at Dunkerque and Boulogne. Concentrations of sediment contaminants at Dunkerque were among the highest of all sites studied (Table 1). Sediment concentrations of PAHs $>600 \mu \mathrm{g} \mathrm{kg}^{-1}$ were recorded in the 3 harbours and the Seine estuary.

A total of 253 0-group sole were analysed, but simultaneous values of the 3 indices (G, Fulton's K and lipid TAG:ST condition indices) measured on each fish were obtained only for 143 individuals with a mean SL of $9.4 \pm 1.53 \mathrm{~cm}$ and a mean weight of $10.03 \pm 3.75 \mathrm{~g}$. Although the size range of fish analysed overlapped substantially among the 7 sites, we found significant differences $(p<0.05)$. Only growth rates showed a significant relationship with SL $\left(\mathrm{r}^{2}=0.572, \mathrm{p}<0.01\right)$. To ovoid a confounding effect of fish size, a growth index $\left(G^{\prime}\right)$ was generated as residuals of the linear regression between SL and G. Variables were log-transformed, which generated a linear relationship and normally distributed residuals.

Although the Pearson correlation coefficient values were moderate $(0.27,0.24$ and 0.40 for $\mathrm{K}$ and TAG:ST, $\mathrm{G}^{\prime}$ and $\mathrm{K}, \mathrm{G}^{\prime}$ and TAG:ST, respectively), the 3 indices were significantly $(p<0.01)$ and positively linked to each other, indicating that these indices followed the same general trends.

The age of the individual 0-group sole analysed varied between 114 and $188 \mathrm{~d}$ (mean age $=142 \pm 16 \mathrm{~d}$ ). Individual growth rates ranged from 0.39 to $0.90 \mathrm{~mm}$ $\mathrm{d}^{-1}$. G' showed significant differences among the 7 sites $(p<0.05$; Fig. 2). Individuals from Calais, Dunkerque, Boulogne and the Seine estuary had slower mean growth indices than fish at the other sites (Table 2). The highest growth index was recorded in

Table 1. Environmental variables for the 7 nursery sites studied: temperature $\left({ }^{\circ} \mathrm{C}\right.$ ), salinity (values in parentheses are mean values recorded between 15 June and 15 September), benthic biomass (AFDW g m${ }^{-2}$ ), sediment chemical contaminants $(\mathrm{Cd}, \mathrm{Cu}, \mathrm{Zn}$, $\left.\mathrm{Hg}, \mathrm{Pb} ; \mathrm{mg} \mathrm{kg}^{-1}\right)$ and polycyclic aromatic hydrcarbons, PAHs $\left(\mu \mathrm{g} \mathrm{kg}^{-1}\right)$

\begin{tabular}{|lccccrrrr|r}
\hline Site & Temperature & Salinity & Benthic biomass & Cd & Cu & Zn & $\mathrm{Hg}$ & $\mathrm{Pb}$ & $\mathrm{PAH}$ \\
\hline 1 Dunkerque & $18.0(17.8)$ & $34.2(34.1)$ & 0.5 & 0.7 & 17.0 & 416.7 & 0.3 & 54.3 & 1090 \\
2 Calais & $17.7(17.8)$ & $34.1(34.1)$ & 48.8 & 0.1 & 6.0 & 66.0 & 0.1 & 18.0 & 720 \\
3 Boulogne & $18.0(18.9)$ & $33.9(33.6)$ & 7.6 & 0.2 & 6.0 & 56.0 & 0.1 & 18.0 & 640 \\
4 Canche & $18.6(18.9)$ & $33.7(33.6)$ & 11.7 & 0.3 & 2.2 & 18.3 & 0.01 & 5.7 & 58 \\
5 Authie & $18.2(19.4)$ & $33.8(32.0)$ & 21.8 & 0.2 & 3.3 & 34.7 & 0.03 & 9.7 & 137 \\
6 Somme & $18.4(19.4)$ & $33.9(32.0)$ & 17.5 & 0.2 & 3.0 & 38.3 & 0.03 & 9.2 & 206 \\
7 Seine & $17.7(18.4)$ & $30.3(30.7)$ & 30.0 & 0.4 & 14.4 & 69.4 & 0.2 & 29.2 & 775 \\
\hline
\end{tabular}


Table 2. Mean values of growth index $\left(\mathrm{G}^{\prime}\right)$, TAG:ST ratio and Fulton's K condition index for 0-group sole at each site and homogeneous groups of sites for $p$ values $<0.05$ resulting from multiple comparison tests (Dunn Test). For site names see Table 1

\begin{tabular}{|c|c|c|c|c|c|c|c|c|c|c|c|}
\hline Site & $\mathrm{N}$ & $\begin{array}{l}\text { Mean } \\
\quad \mathrm{G}^{\prime}\end{array}$ & $\begin{array}{l}\text { Homogeneous } \\
\text { groups }\end{array}$ & Site & $\mathrm{N}$ & $\begin{array}{c}\text { Mean } \\
\text { TAG:ST ratio }\end{array}$ & $\begin{array}{c}\text { Homogeneous } \\
\text { groups }\end{array}$ & Site & $\mathrm{N}$ & $\begin{array}{c}\text { Mean K } \\
\left(\mathrm{mg} \mathrm{mm}^{-3}\right)\end{array}$ & $\begin{array}{c}\text { Homogeneous } \\
\text { groups }\end{array}$ \\
\hline 2 & 23 & -0.08 & * & 1 & 19 & 0.29 & * & 2 & 68 & 1.05 & * \\
\hline 1 & 18 & -0.04 & * & 2 & 21 & 0.35 & * & 7 & 23 & 1.10 & * \\
\hline 7 & 19 & -0.02 & ${ }^{*} \quad *$ & 3 & 22 & 1.05 & * * & 1 & 24 & 1.10 & * \\
\hline 3 & 19 & -0.01 & ${ }^{*} \quad *$ & 7 & 20 & 1.53 & ${ }^{*} \quad *$ & 5 & 36 & 1.19 & * * \\
\hline 5 & 17 & 0.01 & ${ }^{*} \quad *$ & 4 & 21 & 1.61 & ${ }^{*} \quad *$ & 6 & 13 & 1.19 & * * \\
\hline 4 & 13 & 0.11 & * & 5 & 16 & 2.19 & * * & 4 & 34 & 1.20 & * \\
\hline 6 & 19 & 0.11 & * * & 6 & 13 & 2.72 & * & 3 & 55 & 1.21 & * \\
\hline
\end{tabular}

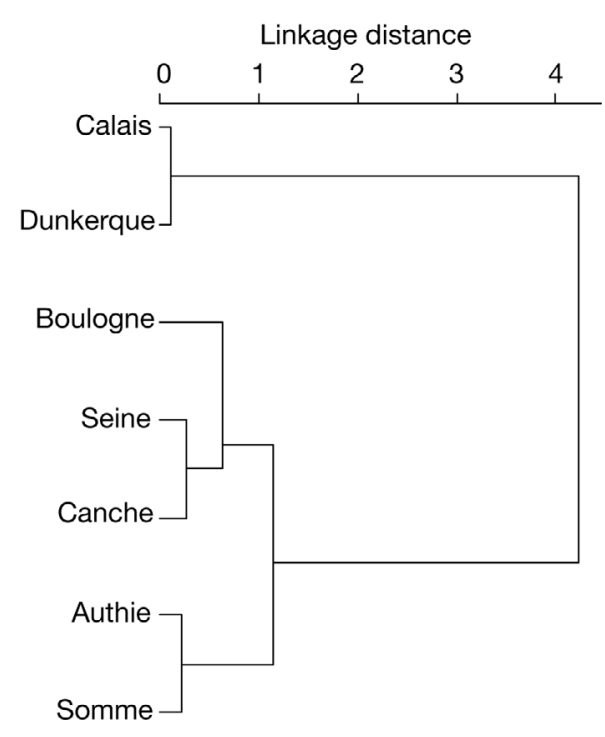

Fig. 3. Solea solea. Dendrogram resulting from the cluster analysis using median values of growth $\left(G^{\prime}\right)$ and condition indices (Fulton's condition index and TAG:ST ratio) and displaying the clustering of the 7 sites analysed

the Somme estuary (0.111) and the lowest at Calais $(-0.079)$.

Similar variation was observed between sites for TAG:ST ratios (Fig. 2). Individual values of TAG:ST ratios varied from 0.01 to 4.36 . Individuals from the 3 harbours (Dunkerque, Calais and Boulogne) had the lowest mean TAG:ST ratios $(<1.07)$ and formed a homogeneous set of sites (Table 2). The estuaries of the Authie and the Somme were characterised by a TAG:ST ratio > 2, whereas the estuaries of the Canche and the Seine had intermediate values (mean TAG:ST ratio $=1.61$ and 1.53 , respectively).

As for the 2 previous indices, Fulton's K also differed significantly among the 7 sites $(\mathrm{p}<0.05)$. Individual values of $\mathrm{K}$ varied from 0.65 to $1.93 \mathrm{mg} \mathrm{mm}^{-3}$. $\mathrm{K}$ was lowest in individuals from Calais (1.045) and Dunkerque (1.096), whereas the highest mean value was recorded at Boulogne (1.214; Table 2).

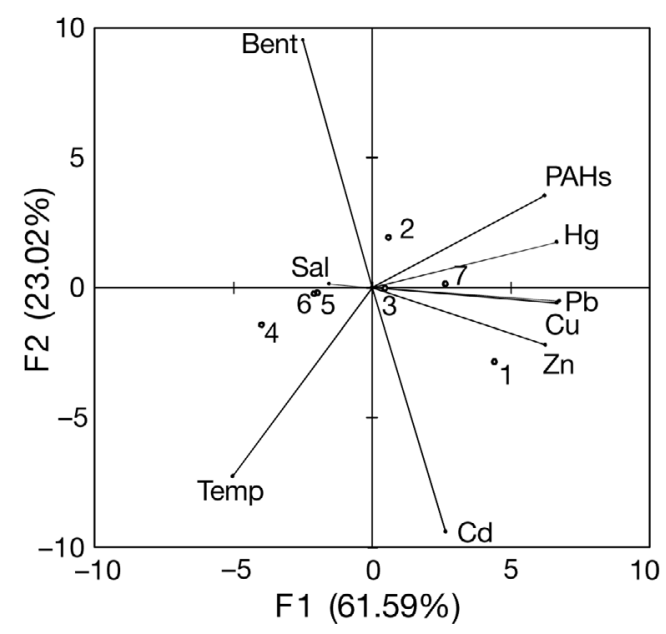

Fig. 4. Solea solea. Biplots for the first and second axis of the PCA based on the environmental and chemical contamination variables (Sal: Salinity; Temp: temperature; Bent: benthic invertebrate biomass; $\mathrm{Cd}, \mathrm{Zn}, \mathrm{Cu}, \mathrm{Pb}, \mathrm{Hg}$ : heavy metals; PAHs: polycyclic aromatic hydrocarbons). Sites are also represented (1 to 7 ; see Table 1 for site names)

When the 3 indices were compared simultaneously, cluster analysis revealed 3 major groups of sites, at a linkage distance of 1.2: group I represented the 2 most industrialised harbours (Dunkerque and Calais), group III included the estuaries of the Authie and the Somme, while group II represented the sites of Canche, the harbour of Boulogne and the Seine estuary (Fig. 3). The last group could be separated into 2 sub-groups at a linkage distance of 0.6: the sites of Boulogne formed a cluster apart from the Canche and Seine estuaries.

Two factors were extracted by applying PCA on environmental and chemical contamination variables, which explained $84.6 \%$ of the total variance $(61.6 \%$ for factor 1 and $23.0 \%$ for factor 2, Fig. 4). Concentration of sediment contaminants explained most of the variance of the first axis. Sites were organised along this axis from less polluted $(4,6$ and 5) to more polluted ones $(2,3,7$ and 1$)$. 


\section{DISCUSSION}

In this study, significant differences were found among the biological indicators measured on juvenile sole collected from nurseries with different degrees of anthropogenic disturbance. 0-group sole grew slowest and had lower condition indices in nursery sites characterised by intense industrial activity and urbanisation, which indicate habitats of inferior quality for juvenile fishes. Growth index, TAG:ST ratios and Fulton's $\mathrm{K}$ condition index measured on juvenile soles were positively correlated and exhibited correspondences with each other and showed consistent systematic differences among the 7 sites. This indicated that these simple biological indicators measured on wild-caught fish are useful to monitor and assess fish habitat quality.

The use of biological indices is based on the assumption that they represent aspects of fish biology directly related to the quality of the habitat where the fish are caught. This assumption would be invalidated if the fish migrate outside or between investigated sites. This was why most previous studies on fish habitat quality have used caging experiments (Able et al. 1999, Meng et al. 2000, 2001, Phelan et al. 2000). However, caging fishes can reduce foraging as well as growth during initial stages due to higher stress (Oikari 2006). Along the French coast of the EEC and the SBNS, sole occur mainly in spatially restricted nursery grounds in soft bottom areas shallower than $20 \mathrm{~m}$ (Eastwood et al. 2003). In addition, like many flatfish species, juvenile sole are strongly habitat-specific during the early juvenile stages (Amara 2003). Following settlement on the nursery, 0-group sole show a strong decline in swimming activity levels during summer, with relatively low activity levels remaining until November (Durieux 2007). Because of the strong habitat association characteristic of this species, growth and condition values of 0-group sole analysed were assumed to reflect the quality of the nursery where they were caught.

Selection and development of biological indicators that can distinguish anthropogenic effects from natural variability is at the heart of habitat quality assessment. When a difference in habitat quality is demonstrated, it is necessary to show that the observed differences are related to human-induced changes and not to natural factors. Comparisons of perturbed to unperturbed habitats provides a way to identify useful biological indicators.

The specific factors negatively affecting growth and condition of juvenile sole are unknown. However, in our work most of the variability in fish growth and condition was explained by the concentrations of sediment contaminants. No effects of hydrological conditions (due to the strong hydrodynamic forces in the areas) or differing food availability effect could be discerned from our observations. In the study areas, the seabed substrate (sand and muddy sand) supported an abundant and a uniform distribution of benthic fauna, which is likely to serve as prey for juvenile sole (Desroy et al. 2003). Previous studies have found juvenile sole to be opportunistic generalists, feeding on a variety of polychaetes, crustaceans and amphipods (e.g. Amara et al. 2001). In EEC and SBNS, comparisons of the observed growth to predicted maximal growth under optimal food conditions suggested that the growth of 0-group sole was only determined by prevailing water temperature and that food was not limiting in the field (Amara et al. 2001). The same was also concluded for other flatfish juveniles in different nursery grounds (Van der Veer et al. 1991).

The nurseries located near the harbours and in the Seine estuary are characterised by high concentrations of a variety of contaminants, including metals and PAHs. Fish growth rates and condition have been widely observed to relate inversely to exposure of the fish to contaminants (Rowe 2003, Alquezar et al. 2006). Burke et al. (1993) showed that the condition and growth of Atlantic croaker Micropogonias undulates were depressed along an estuarine pollution gradient. In 0-group sole, survival, growth, Fulton's $\mathrm{K}$ and the TAG:ST ratio were significantly reduced 3 mo after exposure to hydrocarbon (Claireaux et al. 2004).

Fish growth rates may be a good way to assess habitat quality, provided that fishes grow more quickly in higher-quality habitats, which are those presenting the right set of environmental variables to promote foraging and growth. In our study, mean growth rates $(0.50$ to $0.73 \mathrm{~mm} \mathrm{~d}^{-1}$ ) were comparable to those in other northeastern nursery grounds (see Amara et al. 2001). When fed ad libitum in the hatchery, 0-group sole growth rates may vary from 0.5 to $1.5 \mathrm{~mm} \mathrm{~d}^{-1}$ (Van der Veer et al. 2001). In experiments on exposure to petroleum oil, significant reductions in 0-group sole growth were observed $3 \mathrm{mo}$ after the contamination $(0.45 \mathrm{~mm}$ $\mathrm{d}^{-1}$ for exposed fish and $0.70 \mathrm{~mm} \mathrm{~d}^{-1}$ for control fish), and no sign of recovery was observed even after 6 mo (Claireaux et al. 2004). Juvenile flatfish exposed to hydrocarbon-contaminated sediment displayed a reduced growth 1 to 3 mo after exposure (Moles \& Norcross 1998), and fishes sampled near sewage effluent discharges had lower growth compared to those from control sites (Smith \& Suthers 1999). As suggested by Rowe (2003), there may be energetic explanations for reduced growth rates, such as reductions in feeding or in assimilating energy from food or increases in activity costs by contaminant-exposed fish.

Lipid indices have been used to evaluate environmental stressor effects in fishes (Alquezar et al. 2006). In sole, the fastest growing larvae have been found to 
be those with the highest lipid content (or higher TAG:ST ratio; Amara \& Galois 2004). TAG:ST ratios values in the harbours of Dunkerque, Calais and Boulogne were only one-half to one-sixth those at the other sites studied. The juvenile sole appeared to have depleted energy reserves when living near harbours. Lipid depletion has been identified as a general metabolic response to stress (Lemly 1993, Claireaux et al. 2004). In a mesocosm study, Claireaux et al. (2004) showed that the value of the TAG:ST ratio of juvenile sole exposed during $24 \mathrm{~h}$ to PAHs diminished by $75 \%$ after a 3 mo experiment relative to control fish (mean TAG:ST = 2.34). Metal regulation across cell membranes involves both passive and active mechanisms and therefore requires energy (Alquezar et al. 2006). The main energy source for fish is from lipids (Heath 1995) and may suggest why lipids were lower in fish from polluted nurseries. TAGs are the major energy storage form in fish and have important ecophysiological relevance as indicators of growth potential and survival (Sogard \& Olla 2000). In 0-group sole, lipid storage is generally observed prior to the winter and allows juveniles to survive periods of starvation, which are more frequent in winter (Durieux et al. 2007).

Fulton's K condition index has often been used in stress assessment studies because this type of index is based on easily obtained length and weight measurements. This index is considered a good indicator of the general welfare of the fish and an integrative estimate of environmental conditions (Lambert \& Dutil 1997). Although significant inter-site variations were recorded in the present study, differences were less pronounced than the 2 previous biological indices used. In a mesocosm study, with abundant food and without anthropogenic influences, Laffargue (2004) found that the mean Fulton's K of 0-group sole in September was 1.29. This value is close to those we obtained in the less polluted areas (K values calculated with the fresh total body weight: 1.24 to 1.29), but higher than those obtained in the harbour areas (1.12 to 1.17) except in the harbour of Boulogne. In young sole, Fulton's K condition indices below $0.9 \mathrm{~g} \mathrm{~cm}^{-3}$ reflect a metabolic alteration caused by food shortage associated with lipid storage exhaustion (Fonds et al. 1989). Thus, K values higher than $0.9 \mathrm{~g} \mathrm{~cm}^{-3}$ as recorded in the present study (Table 2) did not indicate starvation or food limitation.

In summary, this study demonstrates that the use of fish growth and condition indices provides a useful tool to compare and assess the quality of essential fish habitat. Like other benthic fish, sole are likely to be exposed to contaminants in sediments because they spend most of their time resting on the sediment and feed on infaunal invertebrates. In addition, because of their morphology and negative buoyancy, sole and flatfish in general have limited behavioural means to respond to environmental fluctuations (Durieux 2007) and are more likely to be exposed to environmentmediated changes in their physiological performance. We attempted to obtain a general diagnostic of the quality of nursery grounds by examining growth and condition of fishes located in areas that were classified according to the degree of anthropogenic pressure. The nurseries located in or near harbours or polluted estuaries do not provide high-quality habitats for juvenile fishes, as is reflected by their lower growth and condition. Metabolic costs may be increased during exposure to pollutants, thus decreasing production processes such as growth and lipid storage (Lemly 1993). Given the complexity of the relationships among organisms, their habitat and multiple potential stressors, it is rarely possible to accurately predict how changes in habitat quality affect living marine resources or to unambiguously detect such changes. However, poor growth and nutritional status of juveniles may weaken overall condition, potentially making these individuals more vulnerable to predation, physiological stress and disease (Adams 2002). Hence the observed low growth rates and condition of juvenile sole could dramatically lower over-winter survival of the juveniles living in or near harbours or polluted nurseries, and thereby reduce recruitment to commercially exploitable stocks.

Acknowledgements. We thank N. Desroy, J. M. Dewarumez and J. C. Dauvin for providing data on benthos biomass. We are grateful to the GIP Seine Aval and the SMBC for providing data on sediment contaminants. We thank Dr. I. R. Jenkinson for English improvement of the manuscript and 3 anonymous referees for constructive comments. This study was financed by the French national program Liteau I (LT 98040).

\section{LITERATURE CITED}

Able KW, Manderson JP, Studholme AL (1999) Habitat quality for shallow water fishes in an urban estuary: the effects of man-made structures on growth. Mar Ecol Prog Ser 187: $227-235$

Adams SM (ed) (2002) Biological indicators of aquatic ecosystem stress. American Fisheries Society, Bethesda, MD

Alquezar R, Markich SJ, Booth, DJ (2006) Effects of metals on condition and reproductive output of the smooth toadfish in Sydney estuaries, south-eastern Australia. Environ Pollut 142:116-122

Amara R (2003) Ichthyodiversity and population dynamics of 0 -group flatfish on a nursery ground in the southern bight of the North Sea (France). Environ Biol Fishes 67(2): 191-201

Amara R, Galois R (2004) Nutritional condition of metamorphosing sole: spatial and temporal analyses. J Fish Biol 64: $72-88$

Amara R, Désaunay Y, Lagardère F (1994) Seasonal variation in growth of larval sole Solea solea L. and consequences 
on the success of larval immigration. Neth J Sea Res 32: $287-298$

Amara R, Laffargue P, Dewarumez JM, Maryniak C (2001) Feeding ecology and growth of 0-group flatfishes (sole, dab and plaice) on a nursery ground (Southern Bight of the North Sea). J Fish Biol 58:788-803

Biro PA, Morton AE, Post JR, Parkinson EA (2004) Overwinter lipid depletion and mortality of age-0 rainbow trout (Oncorhynchus mykiss). Can J Fish Aquat Sci 61: 1513-1519

Bligh EG, Dyer WJ (1959) A rapid method of total lipid extraction and purification. Can J Biochem Physiol 37:911-917

Burke JS, Peters DS, Hanson PJ (1993) Morphological indices and otolith microstructure of Atlantic croaker, Micropogonias undulatus, as indicators of habitat quality along an estuarine pollution gradient. Environ Biol Fishes 36: 25-33

Claireaux G, Désaunay Y, Akca F, Aupérin B and 15 others (2004) Influence of oil exposure on the physiology and ecology of the common sole Solea solea: experimental and field approaches. Aquat Living Resour 17:335-351

Desroy N, Warembourg C, Dewarumez JM, Dauvin JC (2003) Macrobenthic resources of the shallow soft-bottom sediments in the eastern Channel and southern North Sea. ICES J Mar Sci 60:120-131

Durieux EDH (2007) Ecologie du système hôte-parasite, juvéniles G0 de sole-métacercaires de Digènes: dynamique et effets de l'infestation. PhD thesis, La Rochelle University

Durieux EDH, Galois R, Bégout ML, Sasal P, Lagardère F (2007) Temporal changes in lipid condition and parasitic infection by digenean metacercariae of young-of-year common sole Solea solea (L.) in an Atlantic nursery ground (Bay of Biscay, France). J Sea Res 57:162-170

Eastwood PD, Meaden GJ, Carpentier A, Rogers SI (2003) Estimating limits to the spatial extents and suitability of sole (Solea solea) nursery grounds in the Dover strait. J Sea Res 50:151-165

Fonds M, Drinkwaard B, Resink JW, Eysink GGJ, Toet W (1989) Measurements of metabolism, food intake and growth of Solea solea (L.) fed with mussel meat or with dry food. In: De Pauw N, Jaspers E, Ackefors H, Wilkins N (eds) Aquaculture: a biotechnology in progress. European Aquaculture Society, Bredene, p 851-874

Galois R, Lagardère F, Richard P (1990) Change in biochemical composition and otolith microstructure of larval common sole Solea solea L. under experimental starvation. La Mer 28:273-285

Gordon AD (1999) Classification 2nd edn. Chapman \& Hall/CRC, London

Heath AG (1995) Water pollution and fish physiology. CRC Press, Boca Raton, FL

Henry F, Amara R, Courcot L, Lacouture D, Bertho ML (2004) Spatial comparison of heavy metals in fish from the French

Editorial responsibility: Otto Kinne (Editor-in-Chief), Oldendorf/Luhe, Germany coast of the Eastern English Channel and Southern Bight of the North Sea. Environ Int 30:675-683

Laffargue P (2004) Interactions entre comportement individuel et variations de la croissance des juvéniles de sole (Solea solea) dans le réseau trophique des pertuis charentais. PhD thesis, La Rochelle University

Lambert Y, Dutil JD (1997) Can simple condition indices be used to monitor and quantify seasonal changes in the energy reserves of Atlantic cod (Gadus morhua)? Can J Fish Aquat Sci 54:104-112

Lemly AD (1993) Metabolic stress during winter increases the toxicity of selenium to fish. Aquat Toxicol 27:133-158

Meng L, Gray C, Taplin B, Kupcha E (2000) Using winter flounder growth rates to assess habitat quality in Rhode Island's coastal lagoons. Mar Ecol Prog Ser 201:287-299

Meng L, Powell JC, Taplin B (2001) Using winter flounder growth rates to assess habitat quality across an anthropogenic gradient in Narragansett Bay, Rhode Island. Estuaries 24:576-584

Meziane T, Tsuchiya M (2000) Fatty acids as tracers of organic matter in the sediment and food web of a mangrove/intertidal flat ecosystem, Okinawa, Japan. Mar Ecol Prog Ser 200:49-57

Moles A, Norcross BL (1998) Effects of oil-laden sediments on growth and health of juvenile flatfishes. Can J Fish Aquat Sci 55:605-610

Oikari A (2006) Caging techniques for field exposures of fish to chemical contaminants. Aquat Toxicol 78:370-381

Phelan BA, Goldberg R, Bedja AJ, Pereira J and 5 others (2000) Estuarine and habitat-related differences in growth rates of young-of-the-year winter flounder (Pseudopleuronectes americanus) and tautog (Tautoga onitis) in the 3 north-eastern US estuaries. J Exp Mar Biol Ecol 247:1-28

Pihl J, Modin J, Wennhage H (2005) Relating plaice (Pleuronectes platessa) recruitment to deteriorating habitat quality: effects of macroalgal blooms in costal nursery grounds. Can J Fish Aquat Sci 62:1184-1193

Rowe CL (2003) Growth responses of an estuarine fish exposed to mixed trace elements in sediments over a full life cycle. Ecotoxicol Environ Saf 54:229-239

Smith AK, Suthers IM (1999) Effects of sewage effluent discharge on the abundance, condition and mortality of hulafish, Trachinops taeniatus (Plesiopidae). Environ Pollut 106:97-106

Sogard SM, Olla BL (2000) Endurance of simulated winter conditions by age- 0 walleye pollock: effects of body size, water temperature and energy stores. J Fish Biol 56:1-21

Van der Veer HW, Bergman MJN, Dapper R, Witte JIJ (1991) Population dynamics of an intertidal 0-group flounder Platichthys flesus population in the western Dutch Wadden Sea. Mar Ecol Prog Ser 73:141-148

Van der Veer HW, Dapper R, Witte JI (2001) The nursery function of the intertidal areas in the western Wadden Sea for 0-group sole Solea solea L. J Sea Res 45:271-279

Submitted: February 19, 2007; Accepted: July 11, 2007

Proofs received from author(s): November 15, 2007 